\title{
Occupational noise induced vestibular malfunction?
}

\author{
R Hinchcliffe, R R A Coles, P F King
}

\begin{abstract}
This paper comprises a review of the evidence for the possibility that exposure to noise may damage the vestibular receptors in the internal ear as well as those in the cochlea. The review covers lay and medical publications, observations on patients, experimental studies, and compensation claims. It concludes that the verdict must be "not proven"-that is, although such damage is possible, the evidence is not strong enough to regard it as probable.
\end{abstract}

In respect of occupational noise induced hearing loss (NIHL), vertigo is not covered in either the United Kingdom Department of Social Security scheme for "occupational deafness" or in any schemes governed by contract law in the United Kingdom. To the best of our knowledge, no common law judgements exist in which vertigo has been attributed to occupational noise exposure and in which damages have accordingly been awarded. Nevertheless, the question not infrequently arises in particular cases as to whether industrial noise may have damaged the vestibular part of the internal ear as well as the cochlea and thus accounts for a variety of complaints of persistent or recurrent vestibular symptoms. The present paper comprises a review of the evidence for possible noise induced vestibular disorders.

\section{Publications}

Writers can often encapsulate the many aspects of human life including disease, its disabilities, and handicaps. For instance, being born of radical working class parents in Salford, Walter Greenwood ${ }^{1}$ was able to paint a descriptive picture of industrial life there. In Love on the dole he gave an epic description of the life of the working class in the industrial north of England during the period of the depression. $\mathrm{He}$ referred to the "thump of the hammer in the forge

Institute of Laryngology and Otology, Gray's Inn Road, London WC1X 8EE

R Hinchcliffe

MRC Institute of Hearing Research, Nottingham NG7 2RD

R R A Coles

The London Independent Hospital, London E1 4NL P F King which made one giddy . . . the din of the riveting was insufferable ... and every man was stone deaf after six months' work there." However, whereas ". . which made one giddy" is undoubtedly the Tullio $^{2}$ phenomenon (see later), "... every man became stone deaf" can perhaps be attributed to a novelist's inclination to hyperbole rather than a tendency to fabricate.

\section{Field studies}

The first systematic study of occupational noise induced hearing loss in Great Britain was carried out in 1886 by Barr. ${ }^{3} \mathrm{He}$ reported a study of 100 boilermakers in Scotland. Among other things he questioned them regarding giddiness. He wrote, "Only one man stated that he had had such severe giddiness as to amount to attacks of staggering, the attacks not continuing for any length of time, and separated one from another by considerable intervals. In another 14 men there seemed to be occasionally when stooping, or in the morning, when rising out of bed, some sensation of giddiness. But I attributed little importance to these sensations in their bearing upon the state of their ears. It may be said, then, that noises in the ear and giddiness have not been met with anything like the frequency found in cases of ear disease attended by a like amount of impairment of hearing."

In 1915, Rodger ${ }^{4}$ reported his studies on 44 boilermakers and riveters but for his analysis, he included four other subjects who had been seen in the clinic for occupational noise induced hearing loss. Unfortunately, it is not possible to assess the extent to which these cases influenced the results. Rodger recorded that "I obtained a history of this [giddiness] in $10 \%$ of cases. Barr ${ }^{3}$ found it in $14 \%$, and Habermann ${ }^{5}$ in $16 \%$. Neither of these observers attributed much importance to the phenomenon as an integral part of the symptom-complex, but in the light of the most recent work on the vestibular function there is some reason for our looking upon this symptom as an indication of slight concomitant disturbance of the vestibular apparatus."

During the period 1936-39, Larsen ${ }^{6}$ examined (and tested audiometrically) 250 boilermakers and riveters in Odense, Denmark and stated that "from the total material were preliminary omitted 127 men whose condition suggested that other injurious 
influences than noise were at the bottom of their ear disease." Vertigo was not listed as a cause for exclusion. "In the pure material (123 cases), vertigo is a rare symptom, only 5 of the labourers complaining of it. The vestibular function testing did not reveal any abnormalities." In another study of shipyard workers vertigo was reported by $13 \%$ of the 303 men examined but was not regarded as being connected with the working conditions. ${ }^{7}$

Over an 11 month period in 1948-49, Johnston ${ }^{8}$ conducted a study of about 200 workers in the boilermaking, drop forge, and screw manufacturing industries in England. He wrote that "vertigo induced by noise was complained of by only two subjects, both platers with normal ears. It occurred when they were inside a small boiler which was being hammered on the outside by heavy sledge-hammers by four men. Nausea did not result and vertigo passed off within a few minutes of emerging from the boiler." This appears to be more in the nature of a Tullio $^{2}$ phenomenon (vestibular disturbance concomitant on sound stimulation).

In 1951, Dickson and Chadwick ${ }^{9}$ reported the results of interviewing both civilian and military jet engine aircraft workers. The study had been prompted by "injudicious" reports by the mass media of possible harmful effects resulting from engines. This had led to a number of purely psychological disturbances being experienced by jet aircraft engine personnel. Dickson and Chadwick confirmed the occurrence of momentary dizziness, unsteadiness, and mental aberration in personnel working on jet aircraft engines. The symptoms were mild and transitory. Personnel experiencing the symptoms rapidly removed themselves from its influence. No permanent ill effects were seen. The finding did, however, point to the importance of avoiding unnecessary exposure to very high (in excess of 140 $\mathrm{dB}(\mathrm{A})$ ) noise levels. It was suggested that the phenomena were manifestations of the Tullio phenomenon, the symptoms being produced by intense acoustic stimulation of the vestibular labyrinth.

In a study of 344 people with occupational NIHL in the German Democratic Republic, Dieroff and Scholtz ${ }^{10}$ failed to find a correlation between vestibular function measures and hearing level.

Oosterveldt and his colleagues ${ }^{11}$ reported a study conducted on 29 maintenance engineers of Royal Dutch Airlines who had worked in a noisy environment for at least five years and had a sensorineural hearing loss of at least $40 \mathrm{~dB} \mathrm{HL}$ in each ear at $4 \mathrm{kHz}$. "Ten subjects complained of occasional spells of dizziness and sensations of being off balance." None of them had experienced these symptoms in the two years before working in the noisy environment. All 29 subjects were reported to show "pathology in one or more of the vestibular tests." No correlation was found between the degree of vestibular malfunction and the severity of the hearing loss.

It is interesting to compare the above figures with the prevalence of vertigo in the general population. In an MRC survey of a random sample $(n=740)$ of two adult rural populations in the United Kingdom, ${ }^{12}$ $17 \%$ in the age group $18-24$ answered in the affirmative to the question, "Do you suffer, or have you suffered, from dizziness or giddiness?" The figure rose to a $35 \%$ prevalence for the age group 55-64. A subsequent population survey in the United States ${ }^{13}$ showed that $42 \%$ of adults experienced, or had experienced, dizziness. About $7 \%$ of the adults of that country had spells of dizziness that they considered to be severe. In a more recent adult population study in the United Kingdom, ${ }^{14} 61 \%$ of 16964 respondents to the question, "Have you ever suffered from attacks of giddiness, dizziness, unsteadiness or light-headedness?" answered "yes."

\section{Observations on patients}

\section{HISTORICAL}

In his paper in 1831, Fosbroke ${ }^{15}$ reported that "the blacksmiths' deafness is a consequence of their employment; it creeps up on them gradually ... the deafness increases with a ringing in the ears, slight vertigo, and pain in the cranial bones, periodical or otherwise, and often violent." But that statement was made 30 years before Ménière ${ }^{16}$ separated off the episodic labyrinthine malfunctions from the general body of labyrinthine disorders.

\section{CASES OF NOISE INDUCED HEARING LOSS (NIHL)}

Chadwick ${ }^{17}$ reported that 30 of his 160 cases of NIHL had a symptom of "unsteadiness". He stated that dizziness was the only symptom in four cases (the diagnosis of NIHL was apparently made on the basis of an audiogram) and went on: "The symptom of dizziness was often described vaguely, ie as 'slightly off balance', 'maziness', 'dizzy do's' and unsteadiness; as opposed to anything approaching true rotatory vertigo." Two of Chadwick's patients gave an accurate description of the Tullio phenomenon.

A more recent paper ${ }^{18}$ reported that, among 1800 patients with "varying degrees of acoustic trauma," eight patients were "diagnosed as suffering from Ménière's syndrome." Five of these eight patients would probably be correctly designated as having acoustic trauma; the other three as having occupational noise induced hearing loss. These authors used "historical controls" to argue for a causal relation. Had epidemiological data obtained by direct examination of random samples of the general population been used for comparison, it would have appeared that Ménière's syndrome in cases of "varying degrees of acoustic trauma" is less common than in the general population. 
CASES OF MÉNIÈRE'S DISORDER

Pulec $^{19}$ reported that two of his 120 patients with Ménière's disorder developed it "following exposure to loud noise." No further information was given. Paparella and Mancini ${ }^{20}$ reported 18 cases of noise or acoustically induced Ménière's disorder. They stated, however, that "although attempts were made to exclude trauma as a coincidental and not causative factor, in no case can we be absolutely certain trauma was not coincidental because of the uncertainties of the history-taking process." Moreover, occupational noise exposure is specifically mentioned in one case (case 14) only. Even that subject had a history of military noise exposure.

\section{Experimental studies}

In his review of endolymphatic hydrops in experimental animals, Kimura ${ }^{21}$ reported that acoustic trauma or high intensity infrasound produced such histological changes in as many as $35 \%$ of cases. Histological evidence of damage by noise to the vestibular labyrinths was first shown by Wittmaack. ${ }^{22}$ Later studies ${ }^{2324}$ have shown the main effect of intense noise exposure to be mostly limited to the saccule.

\section{Claimants}

Sulkowski ${ }^{25}$ reported that 16 of 335 subjects diagnosed as having occupational NIHL also "suffered vertigo." All of these 16 had worked in noise levels of $120 \mathrm{~dB}(\mathrm{~A})$ or more.

\section{Conclusions}

Vestibular symptoms, whether or not amounting to the complete set of symptoms characteristic of Ménière's disorder and whether or not sustained following acute acoustic trauma, should be clearly distinguished from those purported to arise in association with civilian occupational NIHL.

It would appear that vestibular symptoms may arise from concurrent exposure to high sound levels. As pointed out previously, however, these symptoms are not sustained after removal from the noise source. ${ }^{9}$ The mechanism appears to be in the nature of a Tullio ${ }^{2}$ phenomenon. The balance of evidence is that such vestibular symptoms do not persist after occupational noise exposure has ceased.

But has the failure to show a causal relation between occupational noise exposure and vertigo/ Ménière's disorder been due to the use of subexperimental data? If one accepts that noise can act as a non-specific stress or Wittmaack's concept that endolymphatic hydrops is a non-specific reaction of the internal ear to various factors that damage the labyrinth, one can envisage a number of hypotheses that would support such a relation. For the time being, however, our verdict must be the Scottish one of "not proven"- that is, whereas chronic noise exposure may possibly cause clinically significant vestibular damage, the weight of evidence does not seem strong enough to say that noise has probably caused such damage either as a generality or in an individual case.

This review is based on a committee paper by the first author for the Inter-Society Working Group on Hearing Disability (ISWGHD), which is considering the disabilities arising from noise and other causes of hearing damage. We acknowledge the contributions of our other ISWGHD colleagues, Dr M E Lutman and Professor D W Robinson.

1 Greenwood W. Love on the dole. London: Jonathan Cape, 1933.

2 Tullio P. Sulla funzione delle varie parti dell'orecchio interno. Bologna: Cappelli, 1926.

3 Barr T. Enquiry into the effects of loud sounds upon the hearing of boilermakers and others who work amid noisy surroundings. Proceedings of the Glasgow Philosophical Society 1886; 17:223-9.

4 Rodger TR. Noise deafness: a review of recent experimental work, and a clinical investigation into the effect of loud noise on the labyrinth in boiler-makers. J Laryngol Otol 1915; 30:91-105.

5 Habermann J. Ueber die Schwerhörigkeit der Kesselschmiede. Archiv für Ohrenheilkunde 1890;30:1-25.

6 Larsen B. Investigations of professional deafness in shipyard and machine factory labourers. Acta Otolaryngol (Stockh) 1939: Suppl 36.

7 Siirala U, Lahikainen E. Studies of deafness in shipyard labourers. Acta Otolaryngol (Stockh) 1948;Suppl 67:107-22.

8 Johnston CM. A field study of occupational deafness. $\mathrm{Br} J$ Ind Med 1953;10:41-50.

9 Dickson EDD, Chadwick DL. Observations on disturbances of equilibrium and other symptoms induced by jet engine noise. $J$ Laryngol Otol 1951;65:154-65.

10 Dieroff HG, Scholtz HJ. Zur Frage der Lärmbedingten Vestibülarisschäden bei begutachteten Lärmarbeitem. Zeitschrift für Laryngologie, Rhinologie und Otologie 1967; 46:746-57.

11 Oosterveld WJ, Polman AR, Schoonheyt J. Vestibular implications of noise-induced hearing loss. Br J Audiol 1982;16: 227-32.

12 Hinchcliffe R. Prevalence of the common ear, noise and throat conditions in the adult rural population of Great Britain. British Journal of Preventive and Social Medicine 1961; 15:128-40.

13 DHEW. Hearing status and ear examination: findings among adults. United States, 1960-62. Washington DC: US Public Health Service, National Center for Health Statistics. 1968. (DHEW Series 11, No 32.)

14 Coles RRA, Sinclair A. Vestibular disorders. In: Edwards FC McCallum RJ, Taylor PJ, eds. Fitness for work: the medical aspects. Oxford Medical Publications, 1988:90-100.

15 Fosbroke J. Pathology and treatment of deafness. Lancet 1831; 19:645-8.

16 Ménière $P$. Nouveaux documents relatifs aux lésions de l'oreille interne caractérisés par des symptômes de congestion cérébrale apoplectiforme. Gazette Médicale 1861;16:239-40.

17 Chadwick DL. Acoustic trauma-clinical presentation. Proceedings of the Royal Society of Medicine 1966;59:957-74.

18 Roitman R, Talmi YP, Finkelstein Y, Silver S, Sadov R, Zohar $\mathrm{Y}$. Acoustic trauma-induced Mènière's syndrome. $O R L$ 1989;51:246-50.

19 Pulec JL. Ménière's disease: results of two and one half year study of etiology, natural history and results of treatment. Laryngoscope 1972;82:1703-15.

20 Paparella MM, Mancini F. Trauma and Ménière's syndrome. Laryngoscope 1983;93:1004-12.

21 Kimura RS. Animal models of endolymphatic hydrops. Am J Otolaryngol 1982;3:447-51.

22 Wittmaack K. Ueber Schädigungen des Gehörs durch Schalleinwirkungen. Zeit Hals Nasen Ohren 1907;54:37-42.

23 McCabe BF, Lawrence $M$. The effects of intense sound on the non-auditory labyrinth. Acta Otolaryngol (Stockh) 1958 49:147-57.

24 Mangabeira-Albernaz PL, Covell WP, Eldredge DH. Changes in the vestibular labyrinth with intense sound. Laryngoscope 1959;69:1478-93.

25 Sulkowski WJ. Industrial noise pollution and hearing impairment. Springfield: US Department of Commerce National Technical Information Service, 1980.

Accepted 8 April 1991 